\title{
Effects of tidal stage and sun angles on intertidal benthic microalgal productivity
}

\author{
J. Pinckney, R. G. Zingmark \\ Department of Biological Sciences, and Belle W. Baruch Institute for Marine Biology and Coastal Research, \\ University of South Carolina, Columbia, South Carolina 29208 USA
}

\begin{abstract}
Motile benthic diatoms exhibit rhythmic vertical migrations that are influenced by tidal and light cycles. As a consequence of these periodic migrations, corresponding periodicities in benthic microalgal production should occur. Using oxygen microelectrodes, hourly measurements of microalgal production were obtained from subaerially exposed cores collected from low-intertidal muddy sediments in North Inlet estuary, South Carolina, USA. Microalgal productivity at low tide was twice that at high tide (mean difference $52 \%$ ) and was significantly correlated with diurnal and tidal periodicities

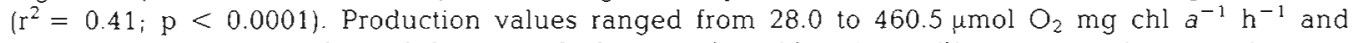
maximum rates were achieved during mid-afternoon low tides. A curvilinear regression equation was constructed to simulate daily and monthly benthic microalgal production based on tidal and light cycles. Comparisons between predictions of the curvilinear equation and published data sets showed a reasonable agreement $\left(\mathrm{r}^{2}=0.77\right)$, suggesting similar phenomena in other estuaries. Current benthic microalgal production models do not account for hourly variability in productivity, leading to potentially large errors when measurements are extrapolated over monthly and annual time scales. Although other physiological and abiotic factors also influence benthic microalgal productivity, much of the short-term variability in production rates may be simply attributed to migratory rhythms within estuarine sediments.
\end{abstract}

\section{INTRODUCTION}

Benthic microalgae (BMA), composed primarily of motile pennate diatoms, occupy the upper few millimeters of sediments and may provide as much as one third of total primary production in some estuarine systems (Sullivan \& Moncreiff 1988). Motile diatoms are capable of rapid movement ( 1 to $25 \mu \mathrm{m} \mathrm{s}^{-1}$ ) and many species vertically migrate within sediments (Round 1971, Edgar \& Pickett-Heaps 1984). As demonstrated in numerous other studies, migrational periodicities are closely correlated with both tidal and diurnal cycles (Palmer \& Round 1967, Palmer 1973, Pearse 1977. Admiraal et al. 1982). During daylight hours, epipelic diatoms migrate upwards when sediments are exposed at low tide and downward as sediments become reimmersed by the incoming tide. BMA may continue vertical migrations with tidal and diurnal rhythmicities for as long as $11 \mathrm{~d}$ when placed under controlled conditions and separated from external stimuli (Palmer \& Round 1967).

Pearse (1977), working in the North Inlet estuary (South Carolina, USA), documented diatom migrations by labeling cells with ${ }^{14} \mathrm{C}$ and observing changes in the vertical distribution of radioactivity over time. Migration was found to be rhythmic, with cells only appearing on the sediment surface at low tide.

Several researchers have reported large differences in BMA productivity in exposed vs immersed sediments and have attributed these differences to vertical migration below the sediment photic zone during immersion (Pomeroy 1959, Darley et al. 1976, Holmes \& Mahall 1982).

As a consequence of migrational rhythms, BMA productivity should exhibit a regular periodicity that is a function of tidal and light cycles. Endogenous photosynthetic rhythms have been reported for salt marsh communities (Brown et al. 1972, Gallagher \& Daiber 1973, Darley et al. 1976), but the relationships between photosynthetic rates and major abiotic factors regulating vertical migration have not been examined. Vertical migration, in addition to other abiotic and biotic factors, may be an important contributor to short-term fluctuations in BMA productivity. The purpose of this study was to determine the degree of hourly variability in BMA productivity and explain some of this variabil- 
ity in terms of factors which regulate vertical migration (i.e. tidal and light cycles). It is not our intent to provide a comprehensive model for BMA production, but rather, to determine the potential effects of tidal and light cycles on production estimates, especially those extrapolated to long temporal scales (e.g. daily, monthly, annually).

\section{STUDY SITE}

The North Inlet estuary $\left(34^{\circ} \mathrm{N}, 79^{\circ} \mathrm{W}\right)$ is a small (3200 ha), bar-built, pocket marsh system located near Georgetown, South Carolina, USA, which experiences semidiurnal tides (mean range $1.7 \mathrm{~m}$ ). This estuary contains numerous small creeks, mudflats, and oyster reefs which are bordered by extensive stands of Spartina alterniflora (Dame et al. 1986). BMA are extremely

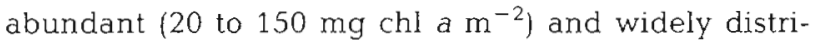
buted throughout the intertidal and shallow subtidal areas of the estuary.

\section{MATERIALS AND METHODS}

During 1989 and 1990, 33 sediment cores were collected at low tide from low intertidal muddy sediments at 6 different locations within the North Inlet estuary. Core tubes, constructed of translucent butyrate tubing $(7.25 \mathrm{~cm}$ dia.), were pushed into the sediment to a depth of 6 to $8 \mathrm{~cm}$. After inserting a spatula under the bottom of the tube, the core was lifted from the sediment, leaving the surface layer of sediment and BMA undisturbed. Cores were returned to the laboratory and stored outside, where natural light-dark cycles were maintained but the effects of tidal inundation were removed. All measurements were made under subaerial conditions at a constant light intensity using artificial light, thereby eliminating irradiance changes due to cloud cover and attenuation by the overlying water.

Gross primary productivity was measured as the rate of oxygen production using Clarke-style oxygen microelectrodes (Diamond General model 737) (Revsbech \& Jørgensen 1986). The microelectrode was connected to a Keithly picoammeter (model 480) and the output logged on a chart recorder. A motorized micromanipulator (Oriel motor-mike) with a digital readout was used to precisely ( $\pm 5 \mathrm{~nm}$ ) position the microelectrode. The productivity measurement method consists of illuminating the sediment sample with a fiber-optic light and measuring the initial slope of oxygen decrease at $50 \mu \mathrm{m}$ depth intervals immediately (within $1 \mathrm{~s}$ ) after darkening the sediment surface (Revsbech \& Jørgensen 1986). The measured rate at each depth interval is then integrated over all the depth intervals to give an areal estimate of gross primary production. Unlike ${ }^{14} \mathrm{C}$ methods, this technique is non-destructive and allows for multiple measurements on the same sample over time.

The theory, accuracy, and reliability of using oxygen microelectrodes for photosynthetic measures has been carefully analyzed and validated in several other studies (Carlton \& Wetzel 1985, Bachmann et al. 1986, Baillie 1986, Dodds 1989, Jensen \& Revsbech 1989, Lindeboom \& Sandee 1989, Hofman et al. 1991). As a simple independent test of the method, photosynthesis was measured in sediment cores before and after the addition of the photosynthetic inhibitors DCMU [3-(3,4dichlorphenyl)-1,1-dimethylurea) $\left(0.03 \mathrm{~g} \mathrm{l}^{-1}\right)$ and formalin $(10 \%)$. As expected, measurements with the microelectrodes showed that oxygen concentrations rapidly decreased and oxygen production ceased after the addition of both inhibitors. Also, the production values obtained with microelectrodes are within the range of values obtained for North Inlet using other techniques (Montagna 1984, Zingmark unpubl.).

Because BMA exhibit microscale $(\mathrm{cm})$ patchiness (Pinckney \& Sandulli 1990), 5 vertical profiles of BMA production were obtained at random locations within each core during each measurement period (ca 20 min). Integrated production was calculated for each depth profile and all 5 profiles were averaged to provide a mean ( \pm 1 standard error) BMA production rate for each core during each measurement period. Microelectrodes were calibrated in seawater collected near the sample site and oxygen concentration in the calibration samples was measured by Winkler titration.

The light intensity $\left(1000 \mu \mathrm{Ein} \mathrm{m}^{-2} \mathrm{~s}^{-1}\right)$ used for all measurements is near saturation intensity for BMA (Fig. 1) (Holmes \& Mahall 1982, Whitney \& Darley 1983 ) and should promote nearly maximal photosynthesis rates $\left(P_{\max }\right)$. Spectroradiometric (Spectron Engineering model CE 500) comparisons between natural sunlight and the fiber-optic light showed no differences in spectral quality. All production measurements were made at temperatures near in situ temperature at the time of collection. Multiple production measurements ( 2 to 11 ), each consisting of 5 production profiles within the core, were taken over time periods of 24 to $48 \mathrm{~h}$, providing a record of variability in BMA production within the same experimental unit (each of the 33 cores) Using the fiber-optic light source, production measurements were made during both day and night to determine diurnal or tidal periodicities in production rates

Chlorophyll a (chl a) concentration was spectrophotometrically determined for the upper $2 \mathrm{~mm}$ depth interval by taking 5 subcores $(1.75 \mathrm{~cm}$ dia.) from each core followed by cold $\left(-10^{\circ} \mathrm{C}\right)$ extraction $(100 \%$ 


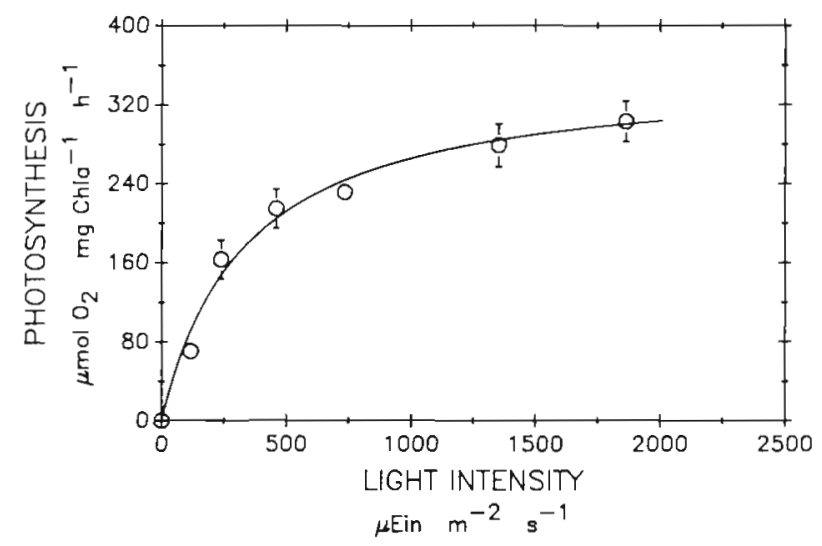

Fig. 1. Typical photosynthesis vs light intensity plot for low intertidal benthic microalgae at the North Inlet estuary. Points are the mean and bars are the standard error of 5 profiles. Where no bars are shown, the standard error was smaller than the symbol drawn

acetone) for $48 \mathrm{~h}$ (Parsons et al. 1984). Samples were shaken twice daily to facilitate extraction. In order to allow multiple measurements on the same core tube, biomass cores were collected after all photosynthetic measures were completed. Differences in productivity were attributed to variations in the amount of biomass in the sediment photic zone (due to vertical migration) rather than changes in photosynthetic capacity. To minimize the effects of heterogeneous spatial distributions of BMA, productivity was converted to units of $\mu \mathrm{mol} \mathrm{O}_{2}(\mathrm{mg} \mathrm{chl} \mathrm{a})^{-1} \mathrm{~h}^{-1}$.

The tidal stage at each measurement can be quantified by transforming the data into tidal angles. Tidal angles are calculated by dividing the time interval between successive high tides by $360^{\circ}$, giving a conversion factor in terms of time per degree. Using the time interval between the previous high tide and the time of the measurement, tidal angles were calculated by multiplying the time interval by the conversion factor, giving a standardized measure of tidal stage. Similarly, the sun angle at a particular time was calculated by dividing the time interval between local sunrise and sunset by $180^{\circ}$ and applying the conversion factor (as described above) to determine the sun angle at the desired time. Angles of 0 and $180^{\circ}$ ( 0 and $\pi$ radians) correspond to tide angles at high and low tide and sun angles at sunrise and sunset, respectively.

\section{RESULTS}

The 33 BMA samples were analyzed during March, April, July, September, and November in 1989 and 1990. Production values ranged from 28.0 to $460.5 \mu \mathrm{mol}$ $\mathrm{O}_{2}(\mathrm{mg} \mathrm{chl} a)^{-1} \mathrm{~h}^{-1}$ while chl a values ranged from
23.88 to $92.67 \mathrm{mg} \mathrm{m}^{-2}$ (Table 1). Although production measurements were made in subaerially exposed cores removed from tidal inundation, rates obtained during the period of low tide in the field were much higher than rates during high tide (1-tailed paired t-test on $\log _{10}$ transformed values, $t=36.775, p<0.001$; Table 2). The average percent difference between rates at high and low tide was $52 \%(S D=21.9)$, implying a 2 fold change in production between high and low tide. Because direct tidal effects (e.g. cover by overlying water, temperature changes, light attenuation by water) were absent during measurements, the observed differences in productivity during high and low tide time periods suggest an endogenous rhythmicity in BMA production.

BMA productivity over hourly time intervals is far from constant, showing an order of magnitude difference within a $12 \mathrm{~h}$ period as well as a regular periodicity (Fig. 2). Two factors that may contribute to this periodicity are tidal stage and sun angle. However, BMA productivity does not show any significant correlations with tidal or sun angles when either factor is examined individually. As a broad generalization, the highest production occurs at tidal angles of 175 to $225^{\circ}$, corresponding to low tide. Similarly, highest productivities generally occur around mid-afternoon. The data are highly variable, suggesting that neither tidal nor sun angles alone account for the periodicity in production rates.

Vertical migration of BMA is strongly affected by the synergistic effects of tidal stage and sun angle. The effects of tidal stage and sun angles were combined in a simple curvilinear regression equation. The negative cosine of the tidal angle reaches a maximum at $180^{\circ}$, roughly corresponding to maximum productivity. The sine of the sun angle reaches a maximum at $90^{\circ}$, corresponding to midday and approximating the time of maximum productivity. Thus, the regression equation takes the following form:

$$
\log _{10} P=A \cos (\mathrm{TIDE}+B)+C \sin (\mathrm{SUN})+D
$$

where $P=$ productivity, TIDE and SUN are tidal and sun angles, respectively, and $A, B, C$, and $D$ are constants (see Table 3 for units). Productivities predicted by this equation are maximal at low tide during the midday hours and minimal at high tide near midnight, roughly corresponding to the maximum and minimum rates observed in the data set.

Using an iterative Marquardt parameter estimation procedure for curvilinear regression (STSC 1987), the equation was fit to the data using the $\log _{10}$ transformed mean production of 5 profiles as the dependent variable and tidal and sun angles at the time of measurement as the independent variables (33 cores, 765 profiles, $\mathrm{n}=153, \mathrm{r}^{2}=0.41, F=4531.7, \mathrm{p}<0.0001$ ) (Table 
Table 1. Summary data for BMA core samples. Number of time intervals refers to the number of times that production was determined during the duration of the experiment. Minimum and maximum photosynthetic rates (PS) are expressed in units of $\mu \mathrm{mol} \mathrm{O}_{2}(\mathrm{mg} \mathrm{chl} \mathrm{a})^{-1} \mathrm{~h}^{-1}$

\begin{tabular}{|c|c|c|c|c|c|}
\hline Core no. & Date & $\begin{array}{l}\text { No. of time } \\
\text { intervals }\end{array}$ & $\begin{array}{c}\text { Mean chl a } \\
\left(\mathrm{mg} \mathrm{m}^{-2}\right)\end{array}$ & Minimum PS & Maximum PS \\
\hline 1 & 15 Mar 1990 & 3 & 52.7 & 96.8 & 406.9 \\
\hline 2 & 15 Mar 1990 & 4 & 54.7 & 64.4 & 272.8 \\
\hline 3 & $15 \operatorname{Mar} 1990$ & 4 & 49.9 & 81.0 & 383.7 \\
\hline 4 & $12 \operatorname{Mar} 1990$ & 5 & 73.4 & 59.6 & 253.3 \\
\hline 5 & 12 Mar 1990 & 5 & 69.4 & 33.6 & 179.6 \\
\hline 6 & $12 \operatorname{Mar} 1990$ & 5 & 75.9 & 28.0 & 226.2 \\
\hline 7 & $12 \operatorname{Mar} 1990$ & 5 & 44.4 & 34.6 & 257.1 \\
\hline 8 & $12 \operatorname{Mar} 1990$ & 5 & 24.5 & 63.4 & 294.4 \\
\hline 9 & $12 \operatorname{Mar} 1990$ & 5 & 23.9 & 82.5 & 200.7 \\
\hline 10 & $16 \mathrm{Jul} 1989$ & 10 & 51.3 & 39.0 & 311.5 \\
\hline 11 & 16 Jul 1989 & 10 & 51.7 & 37.5 & 328.2 \\
\hline 12 & 16 Jul 1989 & 10 & 42.4 & 32.9 & 371.6 \\
\hline 13 & 23 Jul 1989 & 9 & 30.2 & 40.1 & 137.9 \\
\hline 14 & 23 Jul 1989 & 8 & 41.5 & 60.3 & 185.4 \\
\hline 15 & 23 Jul 1989 & 10 & 57.5 & 103.7 & 291.1 \\
\hline 16 & 25 Jul 1989 & 11 & 58.9 & 101.9 & 407.2 \\
\hline 17 & 25 Jul 1989 & 11 & 59.8 & 65.9 & 274.0 \\
\hline 18 & 28 Apr 1990 & 2 & 38.8 & 365.3 & 642.2 \\
\hline 19 & 29 Apr 1990 & 3 & 51.5 & 139.3 & 308.9 \\
\hline 20 & 29 Apr 1990 & 3 & 50.6 & 161.0 & 406.2 \\
\hline 21 & 18 Jull 1990 & 4 & 67.4 & 60.7 & 206.3 \\
\hline 22 & 18 Jul 1990 & 4 & 62.4 & 52.7 & 121.2 \\
\hline 23 & 18 Jul 1990 & 3 & 65.4 & 57.9 & 148.8 \\
\hline 24 & 20 Jul 1990 & 3 & 53.4 & 143.2 & 460.5 \\
\hline 25 & 22 Jul 1990 & 3 & 92.7 & 171.7 & 319.5 \\
\hline 26 & 21 Sep 1990 & 5 & 78.6 & 56.4 & 187.6 \\
\hline 27 & 21 Sep 1990 & 5 & 77.1 & 42.6 & 138.6 \\
\hline 28 & 21 Sep 1990 & 6 & 85.0 & 36.4 & 300.6 \\
\hline 29 & 24 Sep 1990 & 3 & 49.5 & 58.8 & 75.1 \\
\hline 30 & 24 Sep 1990 & 3 & 46.6 & 64.0 & 139.7 \\
\hline 31 & 3 Nov 1990 & 2 & 39.0 & 165.0 & 186.9 \\
\hline 32 & 5 Nov 1990 & 2 & 31.0 & 161.6 & 343.9 \\
\hline 33 & 5 Nov 1990 & 3 & 51.4 & 236.0 & 309.3 \\
\hline
\end{tabular}

3. Fig. 3). Tests for first-order serial autocorrelation (Durbin-Watson) were inconclusive, but residuals were independent and normally distributed. The fit suggests significant tidal and diurnal rhythmicities in BMA productivity. Although only 2 variables were used to describe production in cores collected during different seasons (spring, summer, fall), the significant correlation further illustrates the importance of tide and sun angles in regulating microalgal productivity in intertidal samples.

Using the fitted regression equation to generate values for BMA production demonstrates the combined effects of sun and tidal angles on BMA production periodicity (Fig. 4). In the simulation, maximal rates occur on days with mid-afternoon low tides. Arbitrarily choosing a time of day for productivity measurements will result in a wide range of estimates when tidal stage or sun angles are not taken into account.

The regression equation was also compared to pub- lished data sets to provide some degree of independent validation. The only variables needed for the equation are the time of day at which the measurements were made and the times of high tides during sampling periods. Although the equation provides values (umol $\left.\mathrm{O}_{2}(\mathrm{mg} \mathrm{chl} \mathrm{a})^{-1} \mathrm{~h}^{-1}\right)$ which are difficult to compare with values reported in the published data sets, the predicted values from the model can be compared by standardizing the results in terms of the percentage of the maximum photosynthetic rates. Therefore, the relative rates of production can be calculated for the published data and the equation, providing a direct comparison between measured and predicted relative productivities.

Darley et al. (1976), using ${ }^{14} \mathrm{CO}_{2}$ on subaeriallyexposed cores with constant illumination, measured the microalgal production in creek bank marsh sediments over 2 tidal cycles at Sapelo Island, Georgia, USA. For these data, the model closely tracks the per- 
Table 2. Paired comparisons of benthic microalgal production rates in subaerially-exposed core tubes during periods of high and low tide. Each value is the mean of 5 production profiles and units are $\mu \mathrm{mol} \mathrm{O}_{2}(\mathrm{mg} \text { chl } a)^{-1} \mathrm{~h}^{-1}$

\begin{tabular}{|c|c|c|c|}
\hline Month/year & High tide & Low tide & $\begin{array}{c}\text { Percent } \\
\text { difference }\end{array}$ \\
\hline Mar 1990 & 165.3 & 272.8 & 39.4 \\
\hline Mar 1990 & 177.8 & 316.5 & 43.8 \\
\hline Mar 1990 & 146.6 & 253.3 & 42.1 \\
\hline Mar 1990 & 33.6 & 179.6 & 81.3 \\
\hline Mar 1990 & 28.0 & 140.4 & 80.0 \\
\hline Mar 1990 & 127.8 & 257.1 & 50.3 \\
\hline Mar 1990 & 63.4 & 277.2 & 77.1 \\
\hline Mar 1990 & 106.4 & 229.9 & 53.7 \\
\hline Jul 1989 & 39.0 & 311.5 & 87.5 \\
\hline Jul 1989 & 59.0 & 328.2 & 82.0 \\
\hline Jul 1989 & 41.8 & 371.6 & 88.7 \\
\hline Jul 1989 & 92.5 & 137.9 & 33.0 \\
\hline Jul 1989 & 121.4 & 185.4 & 34.5 \\
\hline Jul 1989 & 148.4 & 267.6 & 44.5 \\
\hline Jul 1989 & 178.2 & 407.2 & 56.2 \\
\hline Jul 1989 & 70.7 & 253.7 & 72.1 \\
\hline Jul 1990 & 60.7 & 206.3 & 70.6 \\
\hline Jul 1990 & 67.3 & 121.2 & 44.4 \\
\hline Jul 1990 & 81.9 & 148.8 & 45.0 \\
\hline Jul 1990 & 143.2 & 460.5 & 68.9 \\
\hline Jul 1990 & 171.7 & 246.4 & 30.3 \\
\hline Sep 1990 & 117.3 & 187.6 & 37.5 \\
\hline Sep 1990 & 94.8 & 120.8 & 21.5 \\
\hline Sep 1990 & 220.2 & 300.6 & 26.7 \\
\hline Sep 1990 & 58.8 & 63.8 & 7.9 \\
\hline Nov 1990 & 161.6 & 343.9 & 53.0 \\
\hline Nov 1990 & 236.0 & 309.3 & 23.7 \\
\hline
\end{tabular}

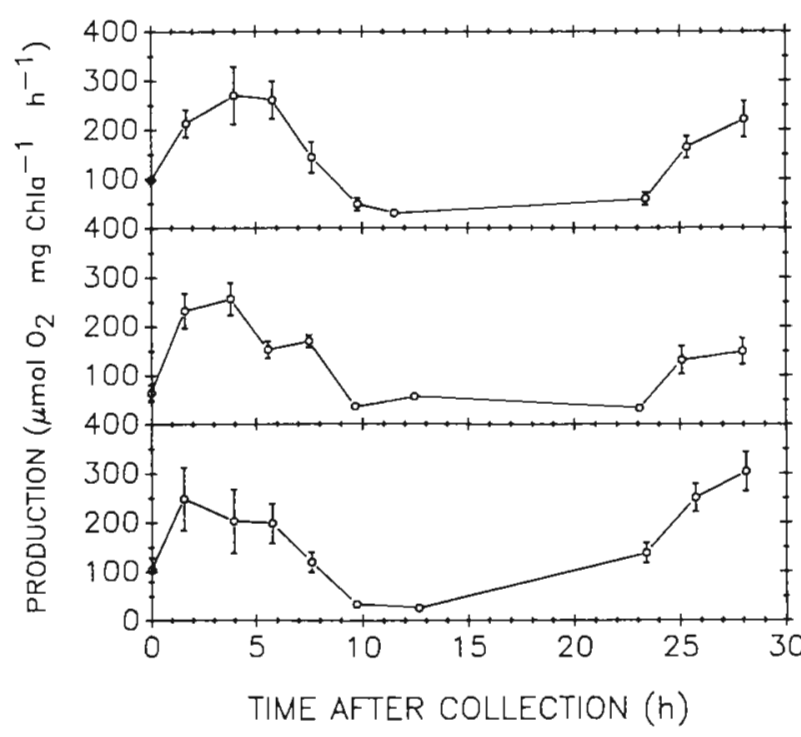

Fig. 2. Examples of time interval productivity measurements which demonstrate the hourly variability in BMA production rates. Each panel contains the data from a single core over the $30 \mathrm{~h}$ time period. Time 0 is the time of the first measurement. Values are mean and bars are standard error of 5 profiles
Table 3. Estimation of curvilinear regression equation coefficients. The curvilinear model was fitted using constants (letters $A$ to $D$ ) which allow for amplitude and phase shifts in the TIDE and SUN curves. The equation is $\log _{10} P=A \cos$ (TIDE + $B)+C \sin (\mathrm{SUN})+D$, where $P$ is BMA production in $\mu \mathrm{mol} \mathrm{O}_{2}$ ( $\mathrm{mg}$ chl a) ${ }^{-1} \mathrm{~h}^{-1}$; TIDE is tidal angle in radians; and SUN is sun angle in radians

\begin{tabular}{|crc|}
\hline Constant & Estimate & Standard error \\
\hline$A$ & -0.1254 & 0.0229 \\
$B$ & -0.5877 & 0.1752 \\
$C$ & 0.3329 & 0.0359 \\
$D$ & 1.9363 & 0.0240 \\
\hline
\end{tabular}

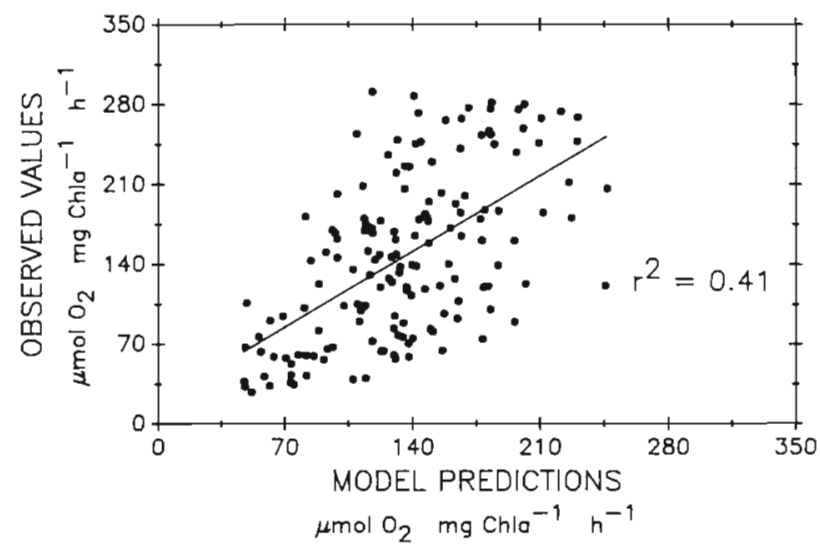

Fig. 3. Observed vs predicted plot for the curvilinear regression model. Equation and constants are given in Table 3

cent maximum photosynthesis of the real values (Fig. 5A). However, the two are slightly out of phase.

Gallagher \& Daiber (1973), using dissolved $\mathrm{O}_{2}$ measurements in submersed cores, measured edaphic microalgal production in cores collected from tall and short Spartina zones of the marsh at Lewes, Delaware, USA. For measurements in the tall Spartina zone, the model shows good agreement with their data, except for the early morning measurement (07:30 h) (Fig. 5B). Although BMA productivity in the short Spartina zone is nearly constant, the model seems to predict the times of maximum photosynthesis (Fig. 5C). However, the model overestimates the variability between the maxima. The lack of agreement between the model and the real data may be related to the elevation of the short Spartina zone. The tidal effects in this area are greatly reduced relative to the low intertidal zone. A leastsquares linear regression of the data in Fig. 5A, B showed a good agreement between the predicted and observed percent maximum photosynthesis ( $\mathrm{n}=13$, $\mathrm{r}^{2}=0.77$ ) and the equation slightly underestimates the percent maximum photosynthesis for this data set.

The slight phase shifts noted in the comparisons above may be attributed to the elevation of the sample 


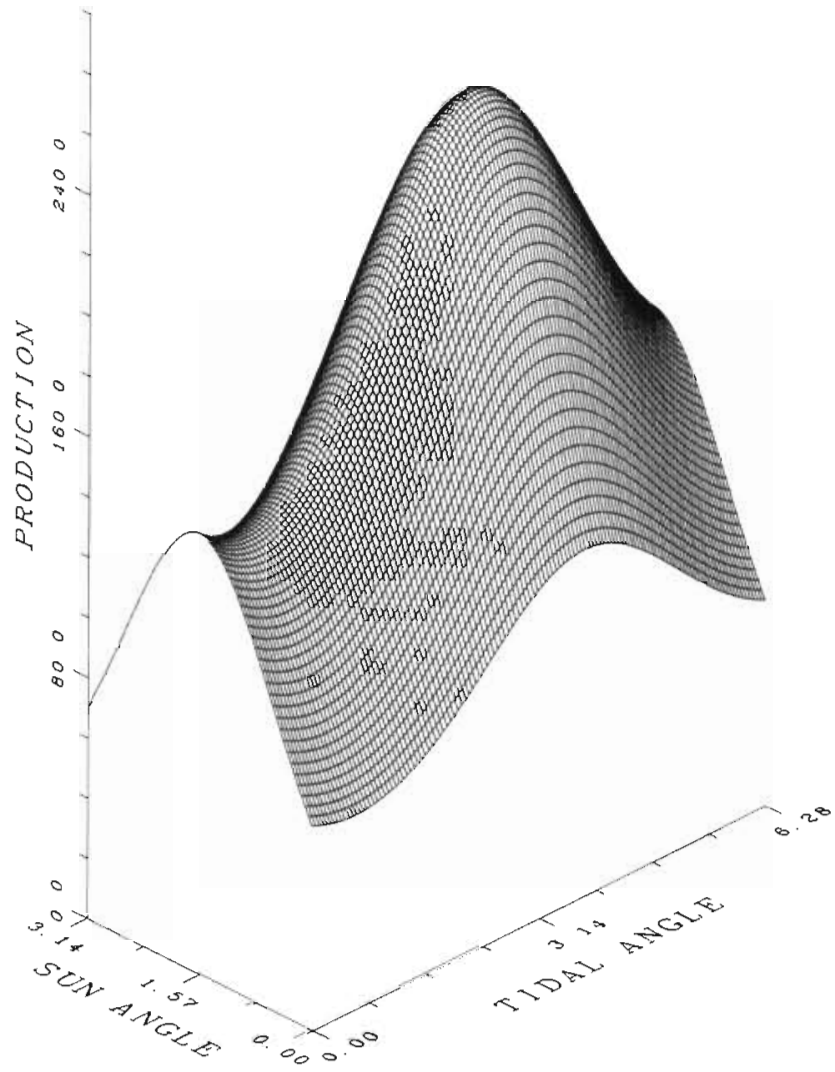

Fig. 4. Predicted values of BMA production based on the fitted regression equation. BMA productivity is constantly changing and maximal rates occur during low tide in the afternoon. Tide and sun angles are in radians and production is expressed as $\mu \mathrm{mol} \mathrm{O} \mathrm{O}_{2}(\mathrm{mg} \mathrm{chl} a)^{-1} \mathrm{~h}^{-1}$

location. Periods of inundation and exposure will vary depending on the elevation. The data used in the regression equation were exclusively from low intertidal mud samples and slight phase shifts would be expected for different tidal elevations.

Brown et al. (1972), working at the River Avon in Bristol, England, provide data which can be used for comparisons. Using uptake of $\mathrm{H}^{14} \mathrm{CO}_{3}$ to measure production of BMA, photosynthetic capacity was linked to the rhythmicity of vertical migration. Comparisons between the predictions from the regression equation and data show that the equation underestimates the relative production rates (Fig. 6). However, when the percent maximum photosynthesis (model) is compared to the number of diatoms migrating to the upper layers of sediment (Fig. 6), the model exhibits a better fit $\left(\mathrm{n}=20, \mathrm{r}^{2}=0.55\right)$. In this case, the regression equation is a poor predictor of percent maximum photosynthesis but is comparable to the abundance of migrating BMA. The obvious changes in photosynthetic capacity may explain the lack of agreement between predicted and observed rates of photosynthesis.

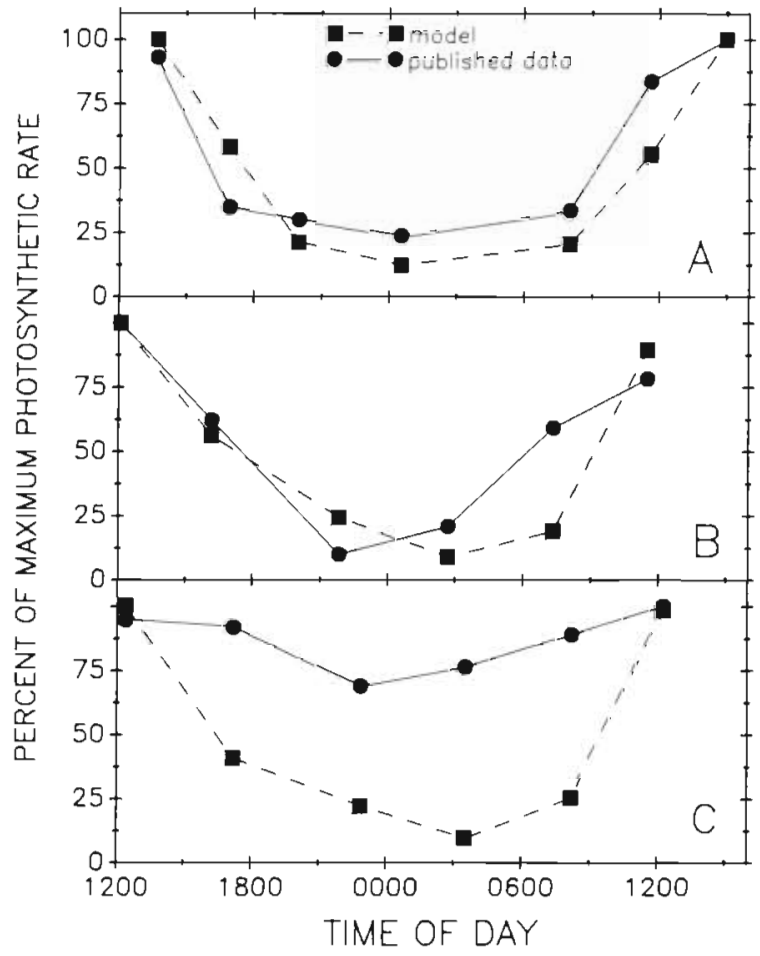

Fig. 5. Comparison of regression model predictions and published data. Values are percent maximum photosynthesis for both model and data. Sample locations for (A), (B), and (C) were creekbank sediments, tall Spartina zone, and short Spartina zone, respectively. Data for (A) were obtained from Darley et al. (1976) and for (B) and (C) from Gallagher \& Daiber (1973). For (A) and (B), percent maximum photosynthesis of the model and published data are significantly correlated $\left(r^{2}=0.77, n=13\right)$

To illustrate the combined effects of tide and light cycles over daily time scales, the regression equation was used to simulate monthly BMA production by using tidal and light data as forcing functions. The regression equation actually provides estimates of potential productivity at a constant light intensity (1000 $\mu$ Ein $\mathrm{m}^{-2} \mathrm{~s}^{-1}$ ) during all hours of the day and night. Obviously, there is no sunlight during the evening hours and BMA production cannot occur at night. By limiting the period of production to the daylight interval in which sunlight exceeds $1000 \mu$ Ein m ${ }^{-2} \mathrm{~s}^{-1}(08: 00$ to $17: 00 \mathrm{~h} \mathrm{EST}$ ), daily estimates of BMA production can be calculated. By summing the daytime hourly rates, an integrated daily rate can be determined given tidal stages and times. Using this procedure, daily BMA production rates were simulated for July 1989 using tidal and light data for the North Inlet estuary (Fig. 7). BMA production exhibits a regular oscillation that is both a function of sun and tide. The days of lowest production are days when high tide occurs during the afternoon, while the days of highest production occur during afternoon low tides. 


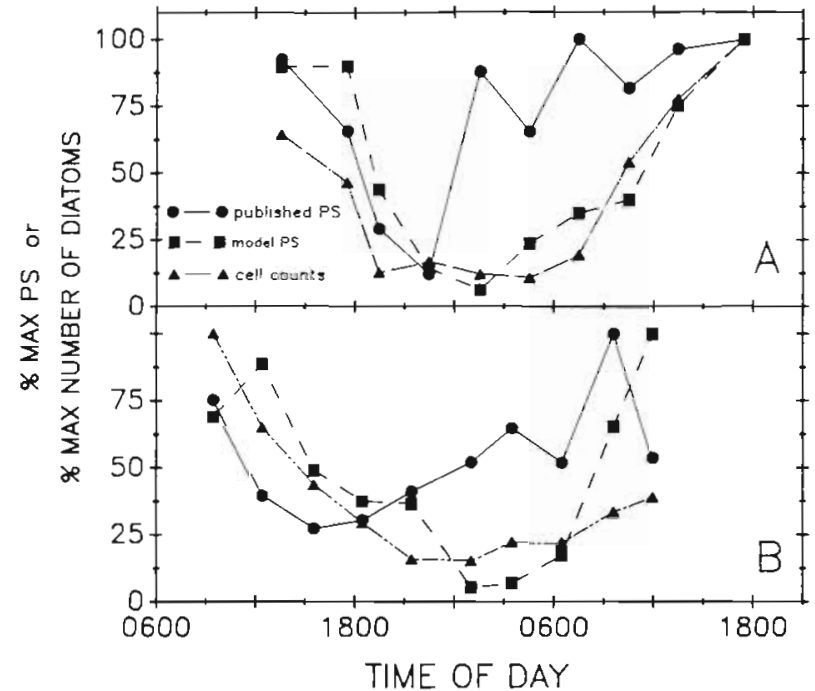

Fig. 6. Comparison of regression model predictions and published data. Percent maximum photosynthesis of the model is compared to both percent maximum photosynthesis and diatom cell counts determined by Brown et al. (1972). Due to changes in photosynthetic capacity (the ratio between published PS and cell counts is not constant), the model does not fit the published percent maximum photosynthesis values. However, diatom cell counts and model percent maximum photosynthesis are significantly correlated $\left(\mathrm{r}^{2}=0.55, \mathrm{n}=20\right)$

\section{DISCUSSION}

The exact relationship between biomass and production is difficult to obtain for the sediment photic zone (usually from 200 to $500 \mu \mathrm{m}$ ). Ideally, the chl a concentration in the sediment photic zone should be determined for each production profile. Core freezing and microtome sectioning could be used to obtain such fine-scale sections, but this method promotes severe vertical distortion of sediment layers (Rutledge \& Fleeger 1988). Another problem with thin sections is that the sediment surface is rarely flat, making it difficult to define the surface plane as a basis for vertical measurements. Because of the migratory nature of the diatoms, cores must be sectioned immediately following the production measurements, thereby destroying the sample and preventing multiple measurements over time.

We chose an alternative approach that sampled the upper $2 \mathrm{~mm}$ of sediment at the conclusion of each experimental series. The upper $2 \mathrm{~mm}$ was the smallest depth interval which consistently produced a nearly constant volume of sediment $( \pm 5 \%$; Pinckney unpubl.). The advantage to this approach was that all of the photosynthetically active chl a was collected regardless of the migratory stage and the same volume of sediment was analyzed in each sample. However, we recognize this method resulted in the collection of

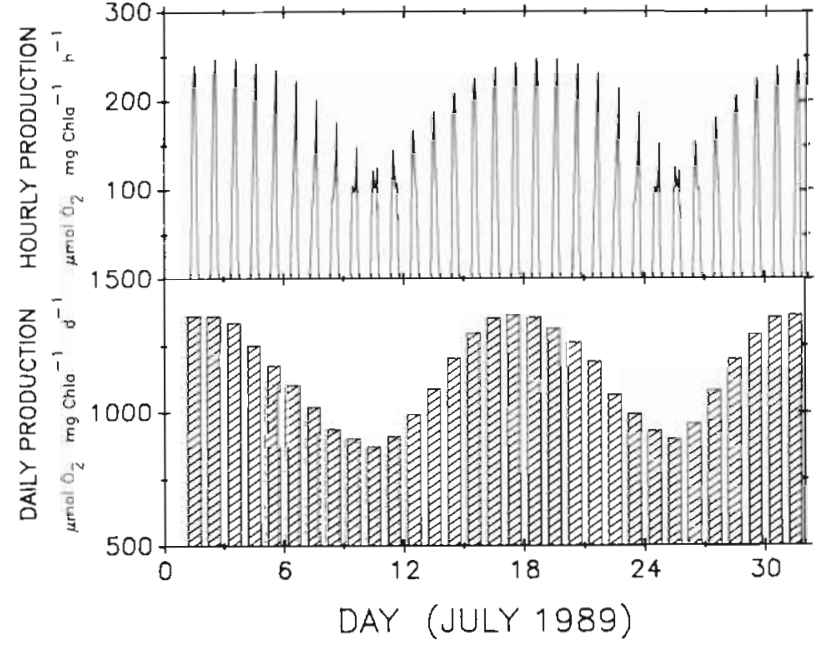

Fig. 7. Example of daily variability in BMA productivity. Using the model equation, tidal angles and transformed times were input to obtain hourly rates between $08: 00$ and 17:00 h EST. Upper panel: hourly productivity during the daylight period; lower panel: integrated daily BMA production. The regular oscillation is due to the lunar cycle which results in high tides occurring $50 \mathrm{~min}$ later on the following day. Total production for July 1989 was $35.780 \mathrm{mmol} \mathrm{O}_{2}$ (mg chl a) $)^{-1}$, while mean daily production was $1154 \mu \mathrm{mol} \mathrm{O}_{2}(\mathrm{mg} \mathrm{chl} \mathrm{a})^{-1} \mathrm{~d}^{-1}(\mathrm{SD}=175)$

chl a from below the photic zone, giving an overestimate of the amount of chl a involved in photosynthesis. Because of the overestimation of photosynthetic chl a by this method, the photosynthetic rates $\left(\mu \mathrm{mol} \mathrm{O}_{2}(\mathrm{mg}\right.$ chl a) ${ }^{-1} h^{-1}$ ) reported above are underestimates of BMA production. In this study, each of the areal production estimates were divided by the mean chl a in the upper $2 \mathrm{~mm}$ of each core to standardize the production measures to BMA biomass. Although this results in an underestimate of photosynthesis when normalized to chl $a$, it does not affect the relative relationships between production, tidal stage, and sun angle.

Rhythmic vertical migration is a well-documented property of epipelic diatoms. Previous studies in the North Inlet estuary have demonstrated that BMA in this system also undergo regular vertical migrations (Pearse 1977). Although several hypotheses have been proposed to explain the dynamics of diatom migrations, most have demonstrated an entrained circadian or 'circalunar' behavior that persists for days when external stimuli are removed (e.g. Palmer 1973). The results of our study suggest a strong periodicity in BMA productivity which is significantly correlated with tidal and light cycles, both factors which are of known importance in vertical migration. A simple curvilinear regression was used to determine the amount of hourly variation in BMA production that could be explained by the synergistic effects of tidal and sun cycles. The regression equation was then used to illustrate the potential effects of this phenomenon on daily and monthly BMA 
production estimates. These results suggest that measurements taken at a single point in time may be of limited value unless the effects of time of day and tidal stage are considered.

Typically, core samples are collected at arbitrary points in time, incubated for 1 to $2 \mathrm{~h}$ periods, and rates are extrapolated to provide monthly and annual estimates of BMA production. Based on our study, such methods are subject to potentially large errors and should not be used until diurnal and tidal periodicities have been examined. In addition, BMA productivity may be site-specific, depending on the combination of tidal range and photoperiod pattern at each particular area. Much of the reported high variability between BMA production rates may be attributed to incubations during different tidal stages and times of day. Shaffer \& Onuf (1985) have evaluated 4 commonly used methods for extrapolating hourly production to daily production, but none of their equations directly account for tidal effects on production rates. In addition, cores are usually immersed during the incubations (regardless of the tidal stage), a condition that probably results in lowered productivity estimates (Pomeroy 1959, Darley et al. 1976, Holmes \& Mahall 1982).

The results of the monthly simulation demonstrate the potential effects of tidal and light cycles on monthly estimates of BMA production. Rates change daily and exhibit high variability at monthly time scales (variance to mean ratio $=26.54$ ). Arbitrarily, or even randomly, choosing sampling days and times will provide little information on true BMA production rates. These results may partially explain the high monthly variability reported for BMA production (see Shaffer \& Onuf 1985).

Despite the wide geographical separation of the data sets used for comparisons (England, Delaware, and Georgia), the regression equation reasonably predicts the relative rates of low intertidal BMA productivity over short time periods. Differences in tidal elevation translate into different tidal periodicities and may partially explain the disparity between the model and independent data sets. In the comparison with the data set provided by Brown et al. (1972) (Fig. 6), a large portion of the short-term variability in BMA productivity appears to be linked to the indirect effects of tidal and light cycles via vertical migration. The relatively good agreement with independent data sets suggests similar BMA production periodicities in other tidallydominated estuaries. These comparisons also suggest that tidal elevation and endogenous changes in photosynthetic capacity are important variables in BMA production.

Although we have attributed the short-term variability in production to endogenous vertical migration, other factors may also be involved. Diel variability in chl a per cell has been documented for planktonic diatoms (Sournia 1974, Owens et al. 1980) and the same phenomenon conceivably occurs in benthic species. Temperature effects have been neglected in our study and could add a third variable to our simple model. The experimental cores were not subjected to tidal inundation during the measurements, suggesting that the observed production periodicities were not directly linked to water effects (e.g. desiccation, bicarbonate concentration, light attenuation). Because the cores were not subjected to tidal flushing during the measurement period, the regular periodicity of physico-chemical conditions in the sediment was altered. Production measurements at successive tidal stages yielded comparable values, suggesting that, over the duration of the experiment, the exposure time did not have a detrimental effect on production.

We have demonstrated a high degree of hourly variability in BMA productivity and attribute this to vertical migrations by epipelic diatoms within the upper layers of low intertidal sediments. Because both light and tidal stage influence migratory rhythms (Palmer \& Round 1967, Palmer 1973, Admiraal et al. 1982), we have correlated these factors with BMA productivity in a simple curvilinear regression model. We do not infer that tidal stage and time of day are the only factors regulating BMA production. Our primary purpose was to demonstrate the importance of these 2 factors when extrapolating BMA production measurements over monthly and annual time scales, rather than provide an independent production model.

Acknowledgements. We thank F. Borrero, D. Lincoln, R. Lovell, R. Feller and 3 anonymous reviewers for their comments on previous drafts. The Delta Institute for Hydrobiological Research, Yerseke, The Netherlands, kindly provided instruction in the use of oxygen microelectrodes. This project was funded by the Slocum-Lunz Foundation and NSF Grant BSR-8514326 (F. J. Vernberg, Principal Investigator). This is publication no. 873 of the Belle W. Baruch Institute for Marine Biology and Coastal Research.

\section{LITERATURE CITED}

Admiraal, W., Peletier, H., Zomer. H. (1982). Observations and experiments on the population dynamics of epipelic diatoms from an estuarine mudflat. Estuar. coast. Shelf Sci. 14: $471-487$

Bachmann, M., Carlton, R., Burkholder, J., Wetzel, R. (1986). Symbiosis between salamander eggs and green algae: microelectrode measurements inside eggs demonstrate effect of photosynthesis on oxygen concentration. Can. J. Zool. 64: 1586-1588

Baillie, P. (1986). Oxygenation of intertidal estuarine sediments by benthic microalgal photosynthesis. Estuar coast. Shelf Sci. 22: 143-159

Brown, D., Gibby, C., Hickman, M. (1972). Photosynthetic rhythms in epipelic algal populations. Br. Phycol. J. 7: 37-44 
Carlton, R., Wetzel, R. (1985). A box corer for studying metabolism of epipelic microorganisms in sediment under in-situ conditions. Limnol. Oceanogr. 30: 422-426

Dame, R., Chrzanowski, T., Bildstein, K., Kjerfve, B., McKellar, H., Nelson, D., Spurrier, J., Stancyk, S., Stevenson, H. Vernberg, J., Zingmark, R. (1986). The outwelling hypothesis and North Inlet, South Carolina. Mar. Ecol. Prog. Ser. 33: 217-229

Darley, W., Dunn, E., Holmes, K., Larew, H. (1976). A ${ }^{14} \mathrm{C}$ method for measuring epibenthic microalgal productivity in air. J. exp. mar Biol. Ecol. 25: 207-217

Dodds, W (1989). Microscale vertical profiles of $\mathrm{N}_{2}$ fixation, photosynthesis, $\mathrm{O}_{2}$, chlorophyll $a$, and light in a cyanobacterial assemblage. Appl. environ. Microbiol. 55: 882-886

Edgar, L., Pickett-Heaps, J. (1984). Diatom locomotion. Prog. Phycol. Res. 3: 47-88

Gallagher, J., Daiber, F. (1973). Diel rhythms in edaphic community metabolism in a Delaware salt marsh. Ecology 54 $1160-1163$

Hofman, P., de Jong, S., Wagenvoort, E., Sandee, A. (1991) Apparent sediment diffusion coefficients for oxygen and oxygen consumption rates measured with microelectrodes and bell jars: applications to oxygen budgets in estuarine intertidal sediments (Oosterschelde, SW Netherlands). Mar. Ecol. Prog. Ser. 69: 261-272

Holmes, R., Mahall, B. (1982). Preliminary observations on the effects of flooding and desiccation upon the net photosynthetic rates of high intertidal estuarine sediments. Limnol. Oceanogr. 27: 954-958

Jensen, J., Revsbech, N. (1989). Photosynthesis and respiration of a diatom biofilm cultured in a new gradient growth chamber. FEMS Microbiol. Ecol. 62: 29-38

Lindeboom, H., Sandee, A. (1989). Production and consumption of tropical seagrass fields in eastern Indonesia measured with bell jars and microelectrodes. Neth. J. Sea Res. 23: $181-190$

Montagna, P. (1984). In-situ measurement of meiobenthic grazing rates on sediment bacteria and edaphic diatoms Mar Ecol. Prog. Ser. 18: 119-130

Owens, T., Falkowski, P., Whitledge, T (1980). Diel periodic-

This article was submitted to the editor ity in cellular chlorophyll content in marine diatoms. Mar. Biol. 59: 71-77

Palmer, J. (1973). Tidal rhythms: the clock control of the rhythmic physiology of marine organisms. Biol. Rev. 48 $377-418$

Palmer, J., Round, F. (1967). Persistent, vertical-migration rhythms in benthic microflora. VI. The tidal and diurnal nature of the rhythm in the diatom Hantzschia virgata. Biol. Bull. mar biol. Woods Hole 132: 44-55

Parsons, T., Majta, Y., Lalli, C. (1984). A manual of chemical and biological methods for seawater analysis. Pergamon, Oxford

Pearse, J. (1977). Radiocarbon tracing of migrating benthic diatoms. M.S. thesis, Univ. of South Carolina, Columbia

Pinckney, J., Sandulli, R. (1990). Spatial autocorrelation analysis of meiofaunal and microalgal populations on an intertidal sandflat: scale linkage between consumers and resources. Estuar coast. Shelf Sci. 30: 341-353

Pomeroy, L. (1959). Algal productivity in salt marshes of Georgia. Limnol. Oceanogr. 4: 386-397

Revsbech, N., Jorgensen, B. (1986). Microelectrodes: their use in microbial ecology. Adv. Microb. Ecol. 9: 273-352

Round, F. (1971). Benthic marine diatoms. Oceanogr mar Biol. A. Rev, 9: 83-139

Rutledge, P., Fleeger, J. (1988). Laboratory studies on core sampling with application to subtidal meiobenthos collection. Limnol. Oceanogr. 33: 274-280

Shaffer, G., Onuf, C. (1985). Reducing the error in estimating annual production of benthic microflora: hourly to monthly rates, patchiness in space and time. Mar. Ecol. Prog. Ser 26: $221-231$

Sournia, A. (1974). Circadian periodicities in natural populations of marine phytoplankton. Adv. mar. Biol. 12: 325-389

STSC (1987). Statgraphics users guide. Statistical Graphics Corporation, Rockville, MD

Sullivan, M., Moncreiff, C. (1988). Primary production of edaphic algal communities in a Mississippi salt marsh. J. Phycol. 24: 49-58

Whitney, D., Darley, W. (1983). Effect of light intensity upon salt marsh benthic microalgal photosynthesis. Mar. Biol. 75: 249-252

Manuscript first received: January 22, 1991

Revised version accepted: June 26, 1991 